\title{
Impactos de la racionalidad multicultural: conflictividad interétnica en el norte del Cauca*
}

\author{
Por Daniella Trujillo Ospina
}

\section{Introducción}

$\mathrm{L}$ a emergencia de la Constitución Política de 1991 y su incorporación del discurso pluriétnico y multicultural implicó el desarrollo de lenguajes y prácticas políticas que desembocaron en un nuevo arte de gobernar o, como diría Nieto (2013), en una gobernanza de la diversidad que ha tenido como suceso coyuntural la activación política de las identidades étnicas. Este contexto de transformación política y cultural marca la consolidación de una nueva estructura de oportunidades políticas para los sujetos étnicos que desde la década de los ochenta fueron constituyéndose como movimientos, hasta ser posteriormente reconocidos y legitimados - en el orden político y jurídico- por la nueva racionalidad estatal, la cual resaltó unos atributos que definieron la condición de los grupos étnicos; no sin dejar de lado que tal racionalidad predispuso en ellos formas distintas de identificación de sí mismos y de percepción de los otros. Es así como el reforzamiento de estas formas étnicas de identificación influyó y determinó muchas de las dinámicas propias de los territorios en los que están inmersos los afrodescendientes e indígenas en Colombia.

\footnotetext{
* $\quad$ Artículo recibido en septiembre de 2015

Artículo aprobado en noviembre de 2015

1 Antropóloga e investigadora del Instituto de Estudios Interculturales de la Pontificia Universidad Javeriana de Cali.
} 
Como tal, debe resaltarse que las zonas rurales en el país se han convertido en los lugares más propensos a desencadenar este tipo de conflictividades, por lo que, igualmente, se han configurado en escenarios en los que se han hecho más visibles las luchas de estas poblaciones étnicas. Debido a lo anterior es importante entender que es ahí, en el ámbito rural, donde históricamente estos grupos se han asentado y han vivido una realidad marcada por la exclusión y la violencia, en un contexto de monopolio y concentración de la tierra (Duarte, 2015). Dichos factores sociales y económicos de la ruralidad en Colombia, sumados a un reforzamiento de la diferencia en el marco de un Estado multicultural, han desencadenado en los últimos veinte años una arena competitiva entre afrodescendientes e indígenas, que intentan ser igualmente reconocidos y cobijados por las promesas materiales del emergente multiculturalismo.

De este modo, pretendo analizar la manera como el reconocimiento de la diferencia ha provocado paradójicamente la emergencia de conflictos entre dos comunidades étnicas del norte del Cauca y ha llevado a que estas agrupaciones legitimen su identidad y fortalezcan su organización política a través de la confrontación con su par étnico, con el ánimo muchas veces de que sean reconocidos sus derechos territoriales y con la aspiración de conseguir los escasos recursos estatales en oferta.

\section{El enfoque relacional de la conflictividad interétnica}

Las formas étnicas de identificación hoy por hoy no solo se han convertido en un instrumento político que ha definido el accionar de comunidades específicas en el marco de los Estado-Nación; sino que igualmente se han constituido como modelos de reconocimiento social y cultural que dan cuenta de especificidades concretas e imaginarias ancladas en una pluralidad de territorios y de relaciones. Entender dichas relaciones interétnicas equivale no solo a comprenderlas en términos de su desarrollo, sino al mismo tiempo en un plano más alto de abstracción que no puede excluir del foco de análisis el carácter sistémico de tales relaciones 
(Cardoso de Oliveira, 2007) y el encuadre político en el que están inevitablemente sumergidas.

En primer lugar, la noción de grupo étnico debe ser comprendida desde un espectro amplio que no condicione este término únicamente hacia un sector o grupo social como tal. Para ello, resulta propicio retomar algunos de los planteamientos de Stavenhagen cuando define el término de grupo étnico de forma intercambiable con "pueblos, comunidades, nacionalidades y, en ocasiones, minorías” (2000, p.12). Tal noción de grupo étnico no solo va a ser comprendida en términos culturales, sino muchas veces en tipos de organización. Según Fredrik Barth:

Los grupos étnicos son formas de organización social socialmente efectivas, debido a que funcionan como categorías de adscripción e identificación que son utilizadas por los actores mismos y que tienen por tanto, la característica de organizar la interacción entre los individuos; [por ello, la identidad étnica es sobre todo] un proceso de adscripción subjetiva de identificación de estatus que se sobrepone a los demás estatus y define sus constelaciones permisibles (1976, p.10).

Tal adscripción deviene entonces de un proceso de identificación en el que una persona hace uso de términos raciales, nacionales, religiosos, para reconocerse a sí mismo dentro de un grupo con unas características particulares y para poder relacionarse con la variedad de sujetos que lo rodean. Ha de resaltarse que el contenido de dicha identidad étnica no se define por criterios de verdad o de autenticidad, "sino por motivaciones políticas que ensamblan conjuntos simbólicos y discursivos asociados a unos orígenes comunes" (Hall, 1992, citado en Pardo, 2002, p.62). Por ello, no puede caerse en el determinismo ideológico, tendiente a pensar de manera utópica, de que estos individuos, y más aún, de que estas agrupaciones son el núcleo de la etnicidad auténtica, pues tal etnicidad es el producto de la articulación y selección de una serie de características que el mismo grupo ha reconocido y definido como propias y distintivas de su organización, destacándolas por encima de otros rasgos y cualidades. 
Así pues, la cuestión étnica permite abordar la problemática de grupos étnicos en relación con el desarrollo histórico de los Estados territoriales (Stavenhagen, 2000); es decir, con el momento específico en el que la nación se constituye como una totalidad integradora e imprime un aura de legitimidad en las relaciones sociales. En este sentido, Cardoso de Oliveira afirma que tal vez uno de los fenómenos más comunes en el mundo moderno es el contacto interétnico; visto entonces como el tipo de "relaciones que se dan entre individuos y grupos de diversas procedencias 'nacionales', 'raciales' o 'culturales' ” (2007, p. 47). El mismo Cardoso de Oliveira se apoya en muchos de los planteamientos de Barth (1976) para sugerir que tales agentes se valen de la identidad étnica para clasificarse a sí mismos; identidad que - debido a su carácter contrastante- implica la "confrontación con otra(s) identidad(es) y la(s) aprehende en un sistema de representaciones de contenido ideológico" (Cardoso de Oliveira, 2007, p.61). Tal confrontación no debe suponer por sí misma la emergencia de un conflicto, pues como advierte Stavenhagen (2000), la diversidad cultural y étnica no necesariamente conduce a un conflicto entre grupos étnicos. Es más, puede decirse que la diversidad, en muchos casos, ha permitido la ampliación de perspectivas por parte de un grupo hacia otro y, con ello, la generación de otros modos de entendimiento y la estructuración de nuevos escenarios de diálogo tejidos a través del reconocimiento de la diferencia.

En cuanto al conflicto como tal, es preciso comprenderlo más bien como una expresión de un antagonismo marcado entre individuos o grupos por la adquisición, posesión y utilización de bienes materiales o simbólicos (riqueza, poder, prestigio, etcétera.) que finalmente tiende a modificar la correlación de fuerzas entre los involucrados.

Para este caso, me he remitido a la definición que construye el equipo del Instituto de Estudios Interculturales - IEI- para dar valor a los conflictos interértnicos manifiestos o latentes dentro del departamento del Cauca desde:

i) la degradación de los mecanismos institucionales y de negociación entre las partes, la posibilidad de recurrir a repertorios de violencia física y 
enfrentamientos colectivos entre los actores en disputa; ii) la existencia de disputas y tensiones históricas entre los procesos organizativos comunitarios y territoriales; y iii) la ausencia, en algunas de las partes, de procesos organizativos consolidados que permitieran organizar mejor las demandas y las negociaciones desde un punto de vista colectivo (Duarte, 2015, p.48).

En sí, la manera como es entendida y abordada la identificación étnica en este caso está inmersa en un conjunto de representaciones configuradas a partir de clasificaciones y oposiciones con ese otro distinto y opuesto. De tal manera que la interrelación entre estos grupos se encuentra cargada de tensiones, desencuentros y múltiples interpretaciones que cada colectividad se hace de sí misma y de los que la circundan. Esto sin dejar de lado el hecho de que estos grupos étnicos se encuentran igualmente inmersos en un sistema de dominación en el que prevalecen ciertos intereses correspondientes a las clases y grupos dominantes y que, "a pesar de que la ideología étnica [es] capaz de promover la base de sustentación de movimientos sociales de cualquier tipo, todos estos movimientos deben ser entendidos como momentos extremos de procesos de articulación social” (Caballero, citado en Duarte, 2015, p.45).

Tal subordinación de las relaciones interétnicas analizadas desde el marco de las relaciones sociales constituidas en los Estados nacionales se ha caracterizado por la lucha que han sostenido una diversidad de grupos sociales desde escenarios locales, regionales y nacionales, con el propósito de lograr un reconocimiento y un trato justo que vaya en sintonía con sus particularidades culturales y sociales. Desde ya, la diversidad constituye un reto para la gobernabilidad de los Estados (Stavenhagen, 2000), que han debido reestructurar sus prácticas y discursos para intervenir en los procesos intrínsecos de las diferentes poblaciones.

Debe resaltarse que las nuevas formas étnicas de identificación pasan a ser una prioridad en estas "mentalidades de gobierno" ${ }^{2}$, produciendo

2 Entendidas como el “conjunto constituido por las instituciones, los procedimientos, análisis y reflexiones, los cálculos y las tácticas que permiten ejercer esa forma [...], de poder que tiene por blanco principal la población, por forma mayor de 
paralelamente que tales identidades estén completamente permeadas por las estrategias de gobernabilidad que el Estado determina, en aras de mantener un ordenamiento social en los territorios y un control sobre las poblaciones. Como bien señala Gros, "bajo estas nuevas formas y con el discurso del respeto a las culturas, a los modos tradicionales de organización colectiva, etc., nunca el Estado estuvo tan presente en los asuntos internos de las comunidades como lo está ahora” (2000, p.105).

Como veremos más adelante, la emergencia de la cuestión étnica en Colombia va a ser determinante dentro de un contexto marcado por profundas transformaciones constitucionales e institucionales implementadas desde principios de la década de los noventa. En este sentido, el término de grupo étnico está primordialmente definido en este país por aquellas identidades basadas en clasificaciones raciales configuradas para grupos poblacionales que fueron mano de obra esclava en la época colonial. Así las cosas, los indígenas y afrodescendientes serán los sujetos étnicos por excelencia en el territorio nacional. De entrada, esta distinción los ubica a ambos en una posición especial dentro del orden social nacional; sin embargo, no deja de percibirse un trato desigual por parte del Estado entre uno y otro grupo, lo que marca un desproporcionado alcance entre el accionar político que va a disponer cada uno.

La desproporción en el trato hacia cada población étnica es solo uno de los factores más visibles que agudiza las relaciones entre dichas agrupaciones. El contexto de conflicto armado latente, las brechas de desigualdad en el campo y en las ciudades, el acaparamiento de tierras desplegado por distintos actores privados y estatales en las zonas rurales, y la presencia diferenciada del Estado y de sus instituciones en las regiones donde ancestralmente se han asentado estos grupos hacen

saber la economía política y por instrumento técnico esencial los dispositivos de seguridad [y] el desarrollo de toda una serie de aparatos específicos de gobierno" (Foucault, 2006, p.136). 
innegable el estado de vulnerabilidad en que se encuentran estos sujetos y, paralelamente, exacerban en ellos la tonalidad de sus exigencias políticas, económicas y sociales. Tales factores conllevan finalmente a que se configure una arena competitiva entre estas comunidades étnicas y culturales (sumando igualmente a la población campesina), y a que se haya desplegado en las últimas décadas un claro deterioro en sus relaciones, puesto que ahora se disputan entre ellas las promesas materiales del emergente multiculturalismo y las deudas que ha dejado en términos territoriales una incipiente reforma agraria en el país.

\section{Emergencia étnica en el Estado colombiano}

La promulgación de la Constitución de 1991 deviene de un contexto marcado por medidas de apertura económica, descentralización y democratización estructuradas desde la década de los ochenta. Esta nueva carta magna es el reflejo de "dos proyectos de sociedad claramente contradictorios: un proyecto humanista, incluyente, que persigue la consolidación de una auténtica democracia participativa para el régimen colombiano, y un proyecto económico neoliberal, a todas luces excluyente" (Jiménez, 2008, p. 47). Desde el proyecto humanista se incorpora entonces el discurso pluriétnico y multicultural que transforma la idea tradicional de nación mestiza y homogénea, para consolidar un Estado que se reconoce desde la diversidad y la diferencia. Mientras tanto, desde el proyecto económico neoliberal se disponen una serie de estrategias y reformas políticas que van en sintonía con las dinámicas propuestas por el Consenso de Washington, en el que se conviene y se respalda la liberalización del comercio exterior, la economía competitiva, la inversión extranjera directa y la privatización (Williamson, 1998).

El cambio propiamente ideológico, según Castillo (2007), representa una transformación de identidades negativas en identidades positivas, lo que implica que indígenas y negros, antes identificados como seres inferiores por los imaginarios cristianizador y civilizador, se convierten en actores sociales que, mediante el uso estratégico de la etnicidad, subvierten las condiciones de dominación e invisibilidad emergentes en el proyecto 
nacional precedente (2007, p.14). En sí, este giro multicultural, aunado a una reorientación de las políticas identitarias en Colombia, revela "la importancia y el papel clave de agentes colectivos antes ignorados en la redefinición de lo público y la ampliación de la ciudadanía" (Chávez y Zambrano, 2009, p.221). Lo anterior supone que asuntos como la discriminación positiva, los derechos diferenciales, el autogobierno y la organización comunitaria y participativa se hayan convertido en aspectos centrales para estos grupos y para el Estado (Nieto, 2013).

Además, dicha ruptura ideológica (Gros, 1993) no debe entenderse sin antes resaltar que este reconocimiento englobó primordialmente a la población indígena, por lo que se explica que haya predominado en las últimas décadas la idea de que los indígenas sean el paradigma de lo que es un grupo étnico (Restrepo, 2013, p.19), y que los afrodescendientes hayan quedado en cierta medida relegados desde el plano discursivo y desde el incumplimiento total de la reglamentación de los artículos de ley que protegen sus derechos especiales ${ }^{3}$. En este sentido, algunas poblaciones negras y mulatas fueron caracterizadas posteriormente como grupo étnico de modo equivalente al de los indígenas; es decir, con base en dos criterios: "[1] la ancestralidad en la ocupación de determinados territorios y [2] la presencia de rasgos específicos en su organización socioeconómica y cultural que empezó a orden global” (Olivier y Urrea, 2004, p.54).

La adopción de estos criterios en la estructuración del artículo 55 de la Constitución, y su posterior reglamentación por medio de la Ley 70 de 1993, llamada también "Ley de Negritudes", estuvo muy influenciada por los procesos organizativos de los movimientos sociales negros en el Pacífico colombiano configurados en la década de los ochenta. Desde

3 La Ley 70 de 1993 o Ley de Negritudes consta de ocho capítulos, siendo el tercero el único que se ha reglamentado hasta el momento. Este capítulo se refiere al reconocimiento al derecho de la propiedad colectiva por medio de la constitución de Consejos Comunitarios; el decreto que lo reglamenta es el 1745 de 1995. 
entonces, "el término étnico-territorial de comunidad negra será hecho extensivo a los demás territorios de la sociedad nacional para captar poblaciones urbanas y rurales que supuestamente se identificasen con una identidad ancestral” (Olivier y Urrea, 2004, p.58).

Tal coyuntura política marcó el "ineludible signo 'Pacífico' de la ley” (Trujillo, 2014), y desencadenó nuevas formas de oposición por parte de la gente negra al manifestar que no se vieron identificados bajo la caracterización social, cultural y económica que establece la Ley 70 de 1993 para referirse a la totalidad de estas comunidades en el país. Así pues, se han generado "diversidad de reacciones y disputas por parte de esas otras comunidades negras que no hacen parte de la Cuenca del Pacífico, desencadenando desde entonces y hasta la actualidad un proceso lento que busca la 'despacificalización' y 'desruralización' de las concepciones asociadas a la Ley” (Trujillo, 2014, p.10).

Como tal, los Consejos Comunitarios localizados en otras zonas del territorio colombiano, al constituirse jurídicamente como autoridades máximas de gobierno de estas comunidades, han luchado fuertemente por el debido reconocimiento de los derechos territoriales pronunciados por la Ley 70 de 1993; la cual, actualmente y de manera exclusiva, se extiende y cobija a aquellas comunidades negras de las zonas rurales, baldías y ribereñas que cumplen con las particularidades territoriales que se han determinado bajo este signo 'Pacífico'.

Todo lo anterior supone un gran reto para las organizaciones de gente negra en Colombia, ya que, en primera instancia, son objeto de un trato diferenciado por parte de un Estado multicultural, que en un comienzo solo acoge y privilegia al indígena como el sujeto étnico emblemático de la nación. Y, en segunda instancia, porque vuelven a ser objeto de discriminación e invisibilización, en este caso, aquellas comunidades negras ubicadas por fuera del Pacífico, al recibir un trato desproporcionado que no reconoce sus especificidades culturales, económicas y sociales, definidas por una noción jurídica que simplemente tiene como 
referente las particularidades de la población negra que se asienta propiamente en el Pacífico colombiano.

\section{Poblamiento y dinámicas locales de la zona norte del departamento del Cauca}

Así las cosas, las comunidades negras de los valles interandinos, en específico las que pertenecen a la zona norte del Cauca, se reconocen como aquellas poblaciones que no han sido valoradas y distinguidas por la Ley de Negritudes "de acuerdo con sus particularidades ancestrales y sus formas de ocupación territorial” (Trujillo, 2014, p.10). Es preciso señalar que estas comunidades de los valles interandinos, a diferencia de las poblaciones negras del Pacífico, se han asentado históricamente en zonas planas extraordinariamente ricas, fértiles y de fácil acceso, lo que ha significado que desde épocas coloniales la estructura de tenencia de la tierra esté determinada por la presencia de propietarios con grandes extensiones territoriales (Observatorio de Territorios Étnicos, 2012, p.18) y por escasos territorios libres de ocupación o de utilización. En contraposición a estas características, muchos territorios del Pacífico colombiano se han caracterizado por ser de difícil acceso, dadas sus condiciones tropicales y selváticas, la cuales han posibilitado que grandes territorios de tierra se hayan constituido en baldíos de la nación, y que, por lo tanto, no hayan sido apropiados y explotados en la misma magnitud que la zona de los valles.

Así pues, abolida la esclavitud en el norte del Cauca, los pobladores negros "lograron acomodarse en poblados campesinos que surgieron de un proceso de apropiaciones legales e ilegales, en un principio clandestinas, de ex-esclavos y sus descendientes en las vastas tierras planas de sus antiguos amos" (Moreno, 2005, p.4). En ese orden de ideas, aquellos libertos que adquirieron tierras en propiedad o que se asentaron en tierras no ocupadas por propietarios tradicionales generaron una economía campesina basada en el minifundio (Observatorio de Territorios Étnicos, 2012, p.52). Los indígenas, por su parte, se mantuvieron 
asentados en las zonas más altas del territorio, con el fin de conservar la propiedad comunal instituida para ellos desde el régimen colonial. Adicionalmente, muchos campesinos negros, y en menor medida indígenas, se dedicaron al jornaleo, razón por la que siguieron manteniendo una marcada dependencia con sus antiguos esclavistas.

En estos territorios donde se asentaron históricamente campesinos negros y población indígena, se destaca paralelamente la presencia de propietarios de minas y terratenientes, quienes con el transcurrir de los años adquirieron terrenos que fueron destinados para cultivos de café, plátano y cacao; además, conformaron de manera paulatina latifundios destinados principalmente a la producción de caña azucarera. Dicho producto fue procesado a niveles cada vez más tecnificados, lo que implicó una menor demanda de mano de obra para las labores de corte y alce.

Ya desde comienzos y mediados del siglo XX, con la emergencia de la industrialización y la conformación de mercados internos en el país (Kalmanovitz, 2003), se destaca la llegada de empresas de carácter privado y estatal en la zona norte del departamento. Estas empresas fundamentaron su crecimiento a través del despliegue de actividades mineras extractivas y de la conformación de un sector dedicado a la agroindustria. Así mismo, desarrollaron megaproyectos de infraestructura, cuyo objetivo primordial fue generar eficiencia dentro del sector productivo e incentivar el desarrollo social. Un claro ejemplo de estos megaproyectos de infraestructura, que dan cuenta de la arremetida capitalista en el territorio, son los que se configuraron con la construcción de la vía Panamericana, que trastornó los canales de comunicación hidrográficos; y los que se llevaron a cabo con la edificación de la represa La Salvajina, que no solo dividió territorios y cambió la disposición productiva de los suelos, sino que también fragmentó lazos entre comunidades y líneas filiales de comunidades étnicas y culturales (Buenaventura y Trujillo, 2011). 
De esta manera, es preciso poner de relieve que esta zona norte del departamento comprendida por 13 de los 42 municipios del Cauca (Ver Mapa 1) ha sido el escenario propicio para extender proyectos de gran envergadura que han estado en sintonía con los designios del capitalismo global, el cual ha buscado incesantemente nuevos espacios de explotación y expropiación (Castillo, 2007, p.348). Lo anterior permite entender que este proceso de acaparamiento de tierras presentado en esta región se ha sumergido en una lógica de valorización del territorio, en tanto se ha convertido en un espacio socialmente vaciable, o lisa y llanamente en un área de sacrificio en aras del progreso selectivo (Svampa, 2013, p.34).

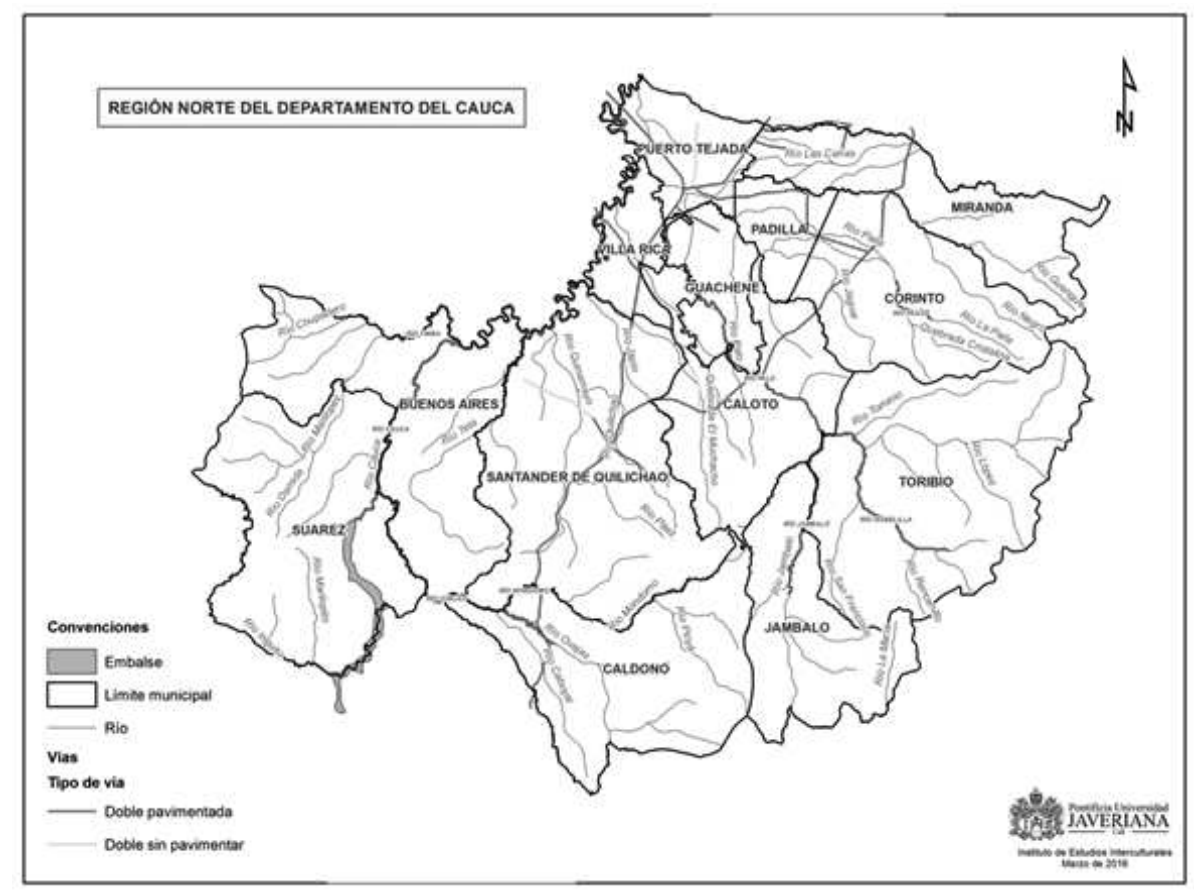

Fuente: Instituto de Estudios Interculturales, 2016 
Aunque parezca contradictorio, dicha lógica de acaparamiento de tierras, movida por intereses propiamente productivos, ha sido también un factor que ha reforzado no solo la lucha efectuada a lo largo de estas últimas dos décadas por comunidades indígenas, negras y campesinas; sino que también se ha convertido en un elemento central a la hora de fortalecer formas esencialistas de identificación basadas en nociones étnicas y culturales. Esto significa, de alguna manera, que la arremetida del capital y la consolidación de proyectos agromineros en este territorio han equivalido también a que estos pobladores se vean en la necesidad de efectuar un proceso de instrumentalización política de sus identidades culturales y étnicas que les permita constituirse como sujeto político ante el Estado (Restrepo, 1997) para la defensa de sus derechos territoriales.

De otro lado, es preciso añadir que, con la construcción de la vía Panamericana, la zona norte se ha convertido en un corredor estratégico para el tráfico de droga y de mercancía ilegal. Tanto esta vía de comunicación, como la geografía escarpada que compone y caracteriza ciertas zonas de los municipios, han hecho de la región un lugar propicio para el movimiento de grupos armados ilegales. Como lo menciona un reciente estudio del Instituto de Estudios Interculturales, "en este contexto, el norte es y ha sido una zona de alto interés para el control de las economías ilegales que giran alrededor del conflicto” (IEI, 2016, p.113).

De hecho, desde la década de los sesenta se ha distinguido la presencia de diferentes grupos al margen de la ley en los municipios nortecaucanos, a tal punto que estos actores se han convertido en los principales responsables de una oleada de desplazamientos forzados generados entre finales de los años ochenta y la primera década del siglo XXI. Tales agrupaciones han ejercido fuertes procesos de control territorial que, ciertamente, han abatido a la población civil y han configurado lógicas fundamentadas en el terror, en la extorsión y en la eliminación de aquel que se concibe como aliado del enemigo. Entre estos grupos de carácter ilegal se encuentran las Farc, encabezadas por el Frente Sexto, el Frente 
Treinta, la columna móvil Jacobo Arenas y el frente Manuel Cepeda Vargas; y el ELN, liderado en esta zona por el frente José María Becerra. A su vez, la proliferación de los recientes grupos de bandas criminales, como las Bacrim, han acoplado la misma lógica extorsiva utilizada por los grupos guerrilleros y se han asentado principalmente en los centros urbanos; lo que ha significado una prolongación -en el tiempo y en el espacio- de la violencia, en territorios que históricamente han sido afectados por el conflicto armado.

Frente a este fenómeno de violencia prolongada en la región, el Estado optó por aumentar su pie de fuerza, para asegurar una mayor presencia de la policía y de las fuerzas militares; sin excluir igualmente el hecho de que desde su aparato administrativo se tejieron redes burocráticas ineficientes y corruptas que profundizaron el conflicto. Este planteamiento advierte que, tanto en el norte como en el resto de regiones que componen el departamento del Cauca, el Estado se ha hecho visible principalmente por una significativa presencia de las fuerzas militares y de la policía, vistas no solo como los órganos legítimos, sino como las entidades idóneas para solventar el conflicto en estas territorialidades, y, adicionalmente, por reproducir unas lógicas burocráticas determinadas por altos niveles de corrupción y clientelismo político. Estos rasgos dan a entender que la manera como se ha encarnado la institucionalidad del Estado en la vida cotidiana de estos pobladores se ha caracterizado por enfrentar el conflicto primordialmente desde su aparato armado, y por consentir formas de administración pública ligadas a prácticas ineficaces e ilícitas que tienden a agudizar las dinámicas de violencia.

\section{Conflictividad interétnica en el norte del Cauca}

La reciente gobernanza de la diversidad adoptada por el Estado colombiano ha tenido impactos significativos en la manera como actualmente conviven y se relacionan las comunidades étnicas y campesinas del norte del Cauca. En específico, es preciso resaltar que esta transformación de la racionalidad de gobierno, no solo ha significado la activación 
política de las identidades étnicas en un nuevo contexto de posibilidades de reconocimiento y legitimación; sino que también ha implicado un reforzamiento de la diferencia hasta el punto de que muchas veces se caiga en un fraccionamiento y distanciamiento entre grupos étnicos. En sí, lo que ha sucedido es que paulatinamente se ha adoptado de manera más recurrente un discurso que ha exacerbado la tonalidad de las diferencias, entendiendo que ahora dichas comunidades

Consideran que tienen prácticas culturales radicalmente diferentes a las de sus vecinos. Así, la colectivización del territorio y la autoridad indígena se consideran radicalmente diferentes a la finca afrodescendiente y a sus baldíos comunitarios, y mucho más lejos de la finca mononuclear campesinomestiza. A pesar de que esta diferencia es sustentable históricamente, llama la atención que los testimonios de los actores evocan que, hace menos de una generación, lo dominante en el interior de sus mismas comunidades eran las prácticas de convivencia intercultural, en las que esas diferencias no eran anuladas pero tampoco eran fuente de conflicto entre comunidades (Duarte, 2015, p.43).

En este sentido, la configuración de estas nuevas representaciones, que cada actor étnico y cultural construye sobre ese otro diferencial, resulta sumamente preocupante cuando ese otro adquiere la imagen de oponente y competidor en un mercado en el que todos aspiran a las mismas tierras y en el que el único modo de acceso, de acuerdo con la Ley 160 de 1994, es la compra de terrenos por parte del Estado.

Todo ello paradójicamente, ha propiciado una arena competitiva antes no existente entre afrodescendientes, indígenas y campesinos que ahora intentan ser igualmente reconocidos y cobijados por las promesas materiales del emergente Estado social de derecho y su incorporación del discurso multiculturalista a todas luces excluyente, al no reconocer la figura del campesino como sujeto de derecho. Resulta entonces pertinente entender este reciente escenario de conflictividad interétnica e intercultural a partir de la tríada en la que se desarrolla la ruralidad 
en el país, la cual según Duarte (2015) se constituye de la siguiente manera: "i) derechos diferenciales, ii) dinámicas del capitalismo rural que conducen a la concentración de la tierra y iii) procesos de construcción política identitaria en el marco del multiculturalismo colombiano" (2015, p.29).

En una región como la del norte del Cauca el contacto entre las agrupaciones étnicas y culturales con presencia en estos territorios ha sido constante, por eso configura un panorama de mayor tensión y fricción en cada encuentro que tiene lugar. Debe señalarse que, solamente en esta zona, hay estructurados 39 Consejos Comunitarios (ver Anexo 1), 13 resguardos constituidos (ver Anexo 2), 10 resguardos coloniales (ver Anexo 2), y además se distingue la presencia de los movimientos campesinos de PUPSOC, ANUC y la organización nacional de la ANZORC.

Esta multiplicidad de territorialidades étnicas y culturales, representadas en el mapa 2, dejan entrever un escenario caracterizado por un amplio despliegue político-organizativo, en el que la cercanía y la proximidad territorial se tornan en elementos que afectan las relaciones entre estas agrupaciones, pues unos y otros se han visto en la necesidad de reforzar sus formas de identificación étnica y cultural para poder acceder a ciertos derechos y reconocimientos. Este ineludible contacto se desarrolla en un contexto en el que el territorio se convierte en la fuente misma de identificación, por lo que este adquiere sentido político en la medida en que estos grupos pretenden legitimar su apropiación (Hoffmann, 2001). 
Mapa 2. Presencia organizativa de afrodescendientes, indígenas y campesinos en el norte del departamento del Cauca

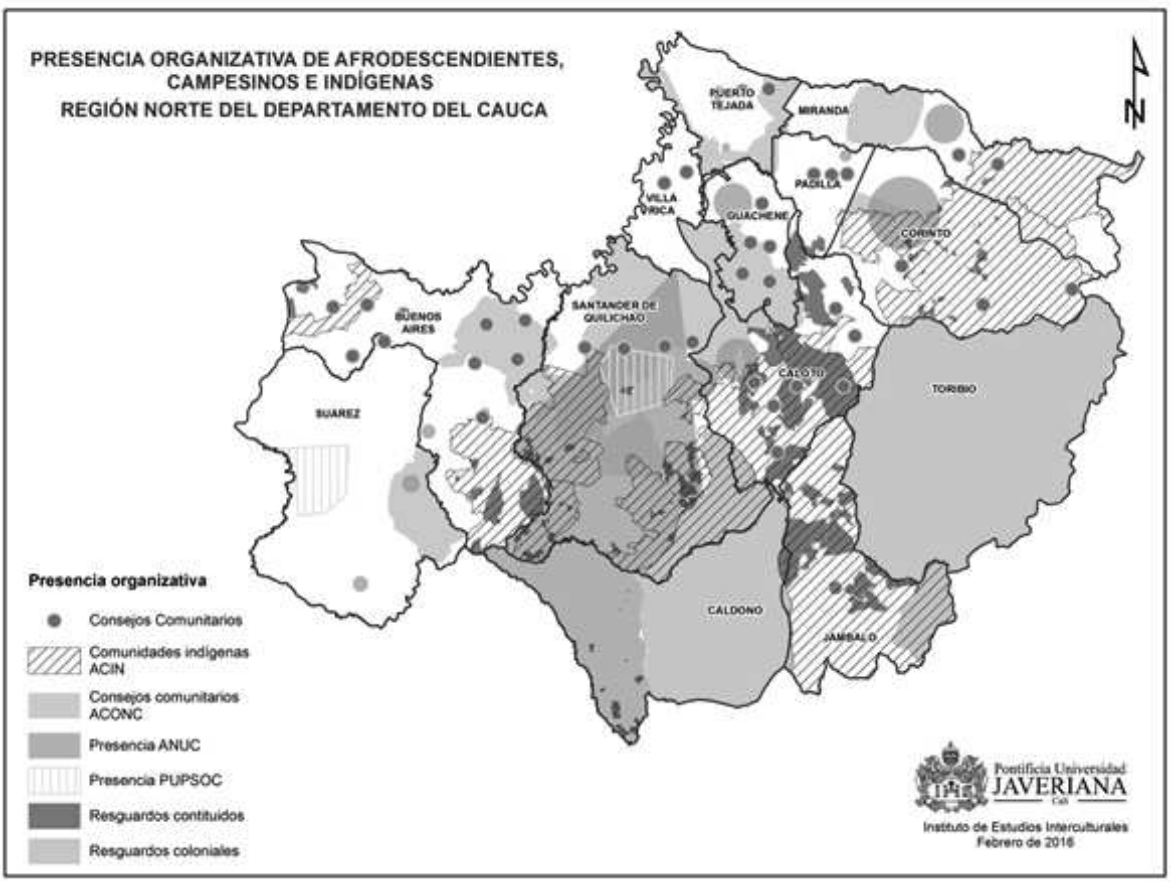

Fuente: Instituto de Estudios Interculturales, 2016

\section{Territorialidades en disputa: el caso de San Rafael y Barrancón}

En este orden de ideas, es clave ahondar en un caso específico de conflictividad interétnica presentado entre la comunidad indígena Nasa del Cabildo de Toribío y las comunidades negras de los Consejos Comunitarios de Zanjón de Garrapatero y de Cuenca del río Cauca. Estos grupos étnicos, en específico el resguardo de Toribío y el Consejo Comunitario Zanjón de Garrapatero, se disputaron en un primer momento la posesión de la finca San Rafael, ubicada en su mayoría dentro de los límites territoriales del municipio de Santander de Quilichao y la zona que colinda con el municipio de Buenos Aires (ver mapa 3). 
El conflicto entre estos indígenas y afrodescendientes emergió cuando el Estado, buscando resarcir a la comunidad indígena de Toribío, decide adjudicarle las 517 hectáreas correspondientes al predio de San Rafael a un costo de $\$ 3.500$ millones. En concreto, el Ministerio del Interior en su afán para dar cumplimiento a las obligaciones que la Corte Interamericana de Derechos Humanos declara al fallar en contra del Gobierno nacional en el caso de la Masacre del Nilo, decide entregar este predio a los indígenas sin consultar previamente con la población negra allí asentada. La Masacre del Nilo fue efectuada el 16 de diciembre de 1991 cuando agentes del Estado, en específico oficiales de la Policía Nacional, fusilaron en la Hacienda El Nilo, ubicada en el municipio de Caloto, a 21 líderes de la comunidad indígena que habían ocupado predios de dicha hacienda. Los agentes destruyeron los ranchos y los enseres de la comunidad con el fin de desalojarlos de los terrenos. Fue así como, el Estado finalmente reconoció su responsabilidad en el hecho y fue obligado a indemnizar a las víctimas (Moreno, 2005). 


\section{Mapa 3. Figuras étnicas y pretensiones territorialescionalismo}

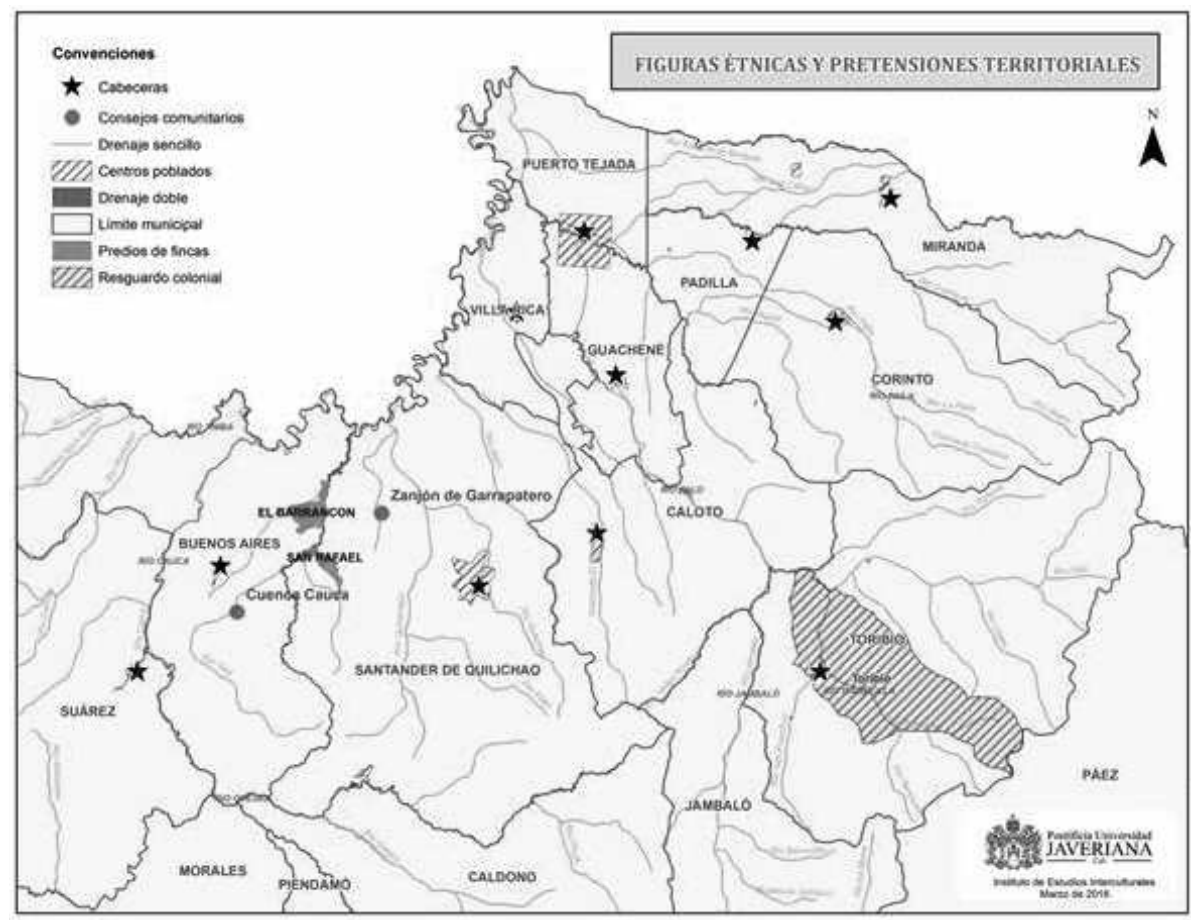

Fuente: Instituto de Estudios Interculturales, 2016

En este proceso de indemnización, el Ministerio del Interior decidió comprar el terreno de San Rafael a los indígenas, ignorando que esta propiedad era utilizada colectivamente por las comunidades afrodescendientes de las Veredas de Mazamorreros localizadas en Buenos Aires y Santander de Quilichao; y, además, desconociendo el hecho de que estas poblaciones han considerado este espacio como su territorio ancestral. En efecto, las comunidades negras al enterarse de esta decisión asumida por el Ministerio se sintieron agredidas y excluidas en el fallo, el cual condujo finalmente a que familias del Resguardo de Toribío se asentaran en la finca, para tomar posesión del territorio entregado legalmente en cumplimiento de la condena. 
De este modo, la convivencia territorial entre los dos grupos se hizo cada vez más difícil y las relaciones entre estos adquirieron un carácter más violento. Como describe Lisifrey Ararat,

La finca se la compran a los indígenas, y ellos colocan allí a un mayordomo que no deja que las comunidades negras hagan uso de ella. Las comunidades negras habían hecho uso de la finca ancestralmente, era de tránsito libre; allí se guardaban los animales, se recogía la leña. Lo que rebozó la copa fue que a la comunidad negra se le empezaron a perder los animales, [...] y cuando la gente de San Rafael empezó a buscar los animales, el mayordomo dijo que no sabía dónde estaban [...]. Se estuvieron enfrentando como dos días, comunidad negra e indígena. Hubo heridos, inclusive dos muertos en ese enfrentamiento (CEI, 2013, p.390).

La fricción en las relaciones y el descontento de la comunidad negra generó un encuentro violento entre unos y otros, lo que desembocó en la trágica muerte de dos miembros indígenas en 2010. Estos hechos dejan entrever que la confrontación desatada entre estas dos agrupaciones se convirtió en un conflicto interétnico, enmarcado en un contexto donde los mismos mecanismos institucionales y la negociación entre las partes se degradaron, hasta el punto de que los repertorios de violencia física se constituyen como el modo más mediato de enfrentar las marcadas diferencias e inconformidades producidas entre los actores involucrados.

Luego de un largo proceso de acompañamiento realizado por el extinto Incoder y el actual Instituto de Estudios Interculturales, se llevaron a cabo varias mesas de diálogo que permitieron llegar a un acuerdo parcial entre estas comunidades étnicas. El acuerdo se basó en la compra del predio El Barrancón para las comunidades indígenas (ver mapa 3) y que la finca San Rafael quedara finalmente en manos de las comunidades negras. Según Alexis Mina, representante legal del Consejo Comunitario Zanjón de Garrapatero,"se convino que el predio de Barrancón, el cual tiene condiciones similares a la finca San Rafael se entregara 
a los indígenas, pero el Consejo Comunitario Cuenca del río Cauca se opuso ya que este predio estaba dentro de su jurisdicción. Por eso se pautó que la mitad del predio fuera entregada a los indígenas y la otra mitad a ese Consejo Comunitario" 4 .

Con estas nuevas condiciones de negociación finalmente se pautó que la finca San Rafael quedara adjudicada a las comunidades negras pertenecientes al Consejo Comunitario Zanjón de Garrapatero. Mientras tanto, los indígenas recibieron la mitad del predio de El Barrancón, es decir, 266 hectáreas, y los afrodescendientes del Consejo Comunitario Cuenca del río Cauca recibieron la otra mitad, alegando que esta propiedad está ubicada igualmente en territorio ancestral de gente negra. Conjuntamente, se acordó contar con $\$ 3,000$ millones más destinados para la adquisición de otra finca para los indígenas con la que puedan solventar unas 249 hectáreas faltantes. Pese a esta última promesa, debe recalcarse que hasta el momento el Resguardo de Toribío no ha recibido de parte del Estado los recursos que quedaron definidos luego de la adquisición de El Barrancón. Ello demuestra el carácter dilatado de los procesos de adjudicación de tierras en el Cauca, pese a que se efectúen compromisos por parte de directivos públicos dentro de escenarios políticos destinados para resolver y dar término efectivo a las demandas y exigencias de las figuras territoriales.

Por su parte, los dos Consejos Comunitarios involucrados en este complejo panorama han sido las únicas autoridades étnico-territoriales de estos dos municipios que vienen adelantando el proceso de titulación colectiva con el gobierno. Esto se debe no solo al protagonismo conferido por este histórico conflicto a lo largo de la región nortecaucana;

4 Relato extraído del video "Relatoría audiovisual:acuerdo interétnico conflicto San Rafael entre indígenas Nasas y Consejos Comunitarios afrodescendientes en el norte del Cauca. Entrevista realizada el 17 de enero de 2013 como parte del diario de campo audiovisual de Carlos Duarte. Consultado el 15 de enero de 2016 desde https://medvedkino.wordpress.com/page/4/ 
sino en igual medida al nivel de interlocución alcanzado por estas organizaciones con diferentes actores políticos y con entidades estatales, sociales y académicas.

En definitiva, lo presenciado entre indígenas y afrodescendientes en este territorio advierte que, aunque el proceso emprendido por el Estado intentó limar asperezas entre ambas comunidades, es innegable que exacerbó el distanciamiento entre estas dos agrupaciones étnicas que ya venía adquiriendo protagonismo gracias al reforzamiento local del discurso multicultural adoptado por el Estado nacional en las últimas dos décadas. Más aún, debe resaltarse que el conflicto interétnico generado en este caso no es consecuencia solamente de estas inadecuadas decisiones estatales, sino también del complejo panorama que han vivido históricamente. Un panorama en el que, además de las problemáticas expuestas anteriormente, estas comunidades ancestrales lidian comúnmente con la llegada de proyectos de corte capitalista a sus territorios en un contexto de monopolio y concentración de la tierra (Duarte, 2015), que ha estrechado sobremanera a las comunidades bajo limitadas extensiones de terreno. Esta situación acentúa la predominancia de microfundios y la escasez de tierra para más y más familias que crecen en el campo. Tampoco se puede dejar de lado que tales fricciones interétnicas han sido potenciadas por una histórica agudización del conflicto armado en regiones rurales, donde la presencia del Estado ha sido concretamente desde la fuerza pública y desde la reproducción de lógicas burocráticas clientelares y corruptas.

Así las cosas, es posible determinar que el profundo fraccionamiento de los lazos sociales y territoriales desencadenado esta última década entre estos grupos étnicos refleja una realidad difícil, puesto que cada grupo se ve en la necesidad de emprender sus luchas y exigencias en vista de que permanente se ve afectada, deteriorada o agotada en su identidad socio-cultural y en su integridad física. De esta manera, se transforman paulatinamente las interpretaciones que cada colectividad se hace de sí misma y de los que la rodean. En este caso, cada comunidad se reconoce 
a partir de unos derechos territoriales y culturales específicos, y, paralelamente, pasa a ver al otro como un oponente y un competidor frente a los escasos recursos estatales en oferta. En este sentido, se hace latente un ambiente de fricción y tensión que irremediablemente exacerba la tonalidad de las exigencias políticas, económicas y sociales de agrupaciones que ahora se reconocen y se legitiman a través de la diferencia, y que, finalmente, no desean que sus proyectos de vida se encuentren enmarcados en un territorio que tiende a estrecharse y a tornarse más hostil.

\section{A modo de cierre}

En último lugar, es posible apreciar que la reciente posibilidad étnica propiciada por la configuración de un Estado multicultural con claros matices neoliberales tiene tres efectos en las subjetividades de los actores étnicos y culturales: 1) el reconocimiento exclusivo de aquellos individuos y agrupaciones que se identifican y representan en términos étnicos, y que en igual medida se caracterizan de acuerdo con los modelos organizativos propuestos en el contenido de las leyes multiculturales y producen paralelamente la exclusión de aquellos que simplemente no pueden ser racionalizados bajo esta manera; 2) el reforzamiento de formas esencialistas de identificación étnica propiciado por la pretendida inclusión sostenida por el discurso multiculturalista, en la que se hacen recurrentes estrategias segmentadas de organización territorial, reclamación de derechos diferenciales y pretensión de recursos estatales para provecho de cada organización; y finalmente subyace 3) la agudización de conflictos interétnicos e interculturales como consecuencia no solo del reforzamiento identitario, sino también de una realidad sumergida en un contexto en el que la tierra disponible es insuficiente y escasa, y en el que la avanzada empresarial de corte capitalista se extiende sobre estos espacios socialmente vaciables donde ha imperado el conflicto armado y ha sobresalido una diferenciada presencia de las instituciones estales. 
La emergencia de estas dinámicas sociales, políticas y económicas pone de relieve el complejo panorama que hoy por hoy enfrenta el país, y el gran reto que supone un ordenamiento del territorio en términos étnicos y culturales. El desafío, además, consiste en transformar la percepción que se tiene de ese otro con el que se convive o se comparte un territorio. Todo ello, con el ánimo de desdibujar aquellas barreras que cercan y estrechan cada vez más estos lugares y que tienden a segmentar las luchas y a aminorar los esfuerzos a través de recurrentes fraccionamientos. Finalmente, la intención se cimienta en el deseo de ampliar el significado y los alcances del sujeto político desde lo público y a través de las particularidades que componen y definen un país construido desde la diferencia.

\section{Bibliografía}

Barth F. (Comp.) (1976). Los grupos étnicos y sus fronteras: la organización social de las diferencias culturales. México: Fondo de Cultura Económica.

Buenaventura, A. y Trujillo, D. (2011). Historia doble del Cauca. Reconstrucción de las historias locales de Suárez y Buenos Aires, Cauca. España: Editorial EAE.

Cardoso de Oliveira, R. (2007). Etnicidad y estructura social. México: Centro de Investigaciones y Estudios Superiores en Antropología Social, Universidad Autónoma Metropolitana, Universidad Iberoamericana.

Castillo, L. C. (2007). Etnicidad y nación: el desafío de la diversidad en Colombia. Cali: Universidad del Valle.

Chávez, M. y Zambrano, M. (2009). Repensando los movimientos indígenas. Flacso - Sede Ecuador, Ministerio de Cultura del Ecuador. Quito, Ecuador.

Duarte, C. (Ed.). (2015). Desencuentros territoriales: la emergencia de los conflictos interétnicos e interculturales en el departamento del Cauca. Bogotá: Instituto Colombiano de Antropología e Historia.

Foucault, M. (2006). Seguridad, territorio, población. Curso en el Collège de France (1977-1978). Buenos aires: Fondo de Cultura Económica. 
Gros, C. (2000). Ser diferente por (para) ser moderno, o las paradojas de la identidad: "Algunas reflexiones sobre la construcción de una nueva frontera étnica en América Latina”. En C. Gross. Políticas de la etnicidad: identidad, Estado y modernidad (pp. 97-115). Bogotá: Instituto Colombiano de Antropología e Historia.

Incoder, Centro de Estudios Interculturales - CEI (2013). Asesoría y acompañamiento para el manejo de las relaciones interétnicas e interculturales para el desarrollo rural. Cali: Pontificia Universidad Javeriana.

Instituto de Estudios Interculturales - IEI (2016). Análisis de la estructura de la propiedad rural en el Cauca. Cali: Pontificia Universidad Javeriana.

Jiménez, A. (2008) Democracia y neoliberalismo: divergencias y convergencias en la construcción de la Carta Política colombiana 1991, Medellín: La Carreta Editores; Universidad Nacional de Colombia, Instituto de Estudios Políticos y Relaciones Internacionales - IEPRI.

Kalmanovitz, S. (2003). Los orígenes de la industrialización. En S. Kalmanovitz (Ed.). Economía y Nación: una breve historia de Colombia (pp. 243301). Bogotá: Editorial Norma.

Moreno, R. (2005). Movimientos étnicos en el norte del cauca, una aproximación a sus diferencias y relaciones. Beca de Investigación CLACSO, sin publicar. [Links].

Nieto, D. (2013). Ethnic conflicts, neoliberal multiculturalism and pluralistic citizenship: Reflections on two cases from Southwest Colombia. En 2013 Congress of the Latin American Studies Association, Washington, D.C.

Observatorio de Territorios Étnicos (2012). Poblaciones negras en el norte del Cauca. Contexto político organizativo. Bogotá: Departamento de Desarrollo Rural y Regional de la Facultad de Estudios Ambientales y Rurales, Pontificia Universidad Javeriana.

Pardo, M. (2002). Entre la autonomía y la institucionalización: dilemas del movimiento negro colombiano. The Journal of Latin American Anthropo$\log y, 7(2), 60-85$.

Restrepo, E. (1997). Afrocolombianos, antropología y proyecto de modernidad en Colombia. En M. V Uribe y E. Restrepo (Eds.). Antropología en la modernidad: Identidades, etnicidades y movimientos sociales en Colombia (pp. 279-319). Bogotá: Instituto Colombiano de Antropología e Historia. 


\section{I Controversia 205}

Restrepo, E. (2013). Etnización de la negridad: la invención de las "comunidades negras" como grupo étnico en Colombia. Popayán: Universidad del Cauca.

Restrepo, E. y Rojas, A. (Eds.) (2004). Conflicto e (in)visibilidad: retos de los estudios de la gente negra en Colombia. Popayán: Universidad del Cauca.

Olivier B. y Urrea, F. (2004). Introducción. En E. Restrepo, y A. Rojas, A. (Eds.) Conflicto e (in)visibilidad: retos de los estudios de la gente negra en Colombia. Popayán: Universidad del Cauca.

Stavenhagen, R. (2000). Conflictos étnicos y Estado nacional. México: Instituto de Investigaciones de las Naciones Unidas para el Desarrollo Social - UNRISD, Siglo XXI Editores.

Svampa, M. (2013, marzo-abril). «Consenso de los Commodities» y lenguajes de valoración en América Latina. Nueva Sociedad, (244), 30-46.

Trujillo, D. (2014). Escenarios de paradojas y posibilidades: empoderamiento étnico-territorial del Consejo Comunitario Cuenca del río Cauca y microcuencas de los ríos Teta y Mazamorrero en el norte del Cauca (Tesis de pregrado). Departamento de Derecho y Ciencias Sociales, Universidad Icesi. Cali, Colombia.

Williamson, J. (1998) Revisión del Consenso de Washington. En L. Emmerij y J. Nuñez del Arco (Eds.). El desarrollo económico y social en los umbrales del siglo XXI (pp. 51-65). Washington: BID. 


\section{Anexos}

Anexo 1. Consejos Comunitarios del norte del Cauca

\begin{tabular}{|c|c|c|c|c|c|}
\hline Municipio & $\begin{array}{c}\text { Consejo } \\
\text { Comunitario }\end{array}$ & $\begin{array}{c}\text { N. }{ }^{\circ} \text { de } \\
\text { familias }\end{array}$ & Municipio & $\begin{array}{c}\text { Consejo } \\
\text { Comunitario }\end{array}$ & $\begin{array}{c}\mathrm{N} .^{\circ} \text { de } \\
\text { familias }\end{array}$ \\
\hline \multirow{7}{*}{ Caloto } & Yarumito & 760 & \multirow{5}{*}{ Guachené } & $\begin{array}{l}\text { Ribera del } \\
\text { río Palo }\end{array}$ & 650 \\
\hline & Santafro & 90 & & $\begin{array}{c}\text { Brisas del río } \\
\text { Palo }\end{array}$ & 800 \\
\hline & QuitaCalzon & 300 & & Tabora & 200 \\
\hline & Bodega Guali & 1.250 & & $\begin{array}{c}\text { Zanjón de } \\
\text { Potoco }\end{array}$ & 120 \\
\hline & $\begin{array}{c}\text { Centro de } \\
\text { Caloto Pandao }\end{array}$ & 11.817 & & Pílamo & 87 \\
\hline & $\begin{array}{c}\text { Consejo } \\
\text { Comunitario } \\
\text { de la } \\
\text { comunidad } \\
\text { negra de } \\
\text { Guachene }\end{array}$ & $\begin{array}{c}\text { Sin } \\
\text { información }\end{array}$ & \multirow[b]{2}{*}{ Miranda } & Ortulín & 486 \\
\hline & $\begin{array}{c}\text { Consejo } \\
\text { Comunitario } \\
\text { de la } \\
\text { comunidad } \\
\text { negra del } \\
\text { corregimiento } \\
\text { Veredas } \\
\text { Noorientales }\end{array}$ & $\begin{array}{l}\text { Sin } \\
\text { información }\end{array}$ & & Comzoplan & 2.300 \\
\hline \multirow{3}{*}{ Corinto } & $\begin{array}{l}\text { Barranco - } \\
\text { Guengue }\end{array}$ & 250 & \multirow{3}{*}{ Padilla } & Unión Yaru & 1.904 \\
\hline & $\begin{array}{l}\text { Jagual - La } \\
\text { María }\end{array}$ & 75 & & $\begin{array}{c}\text { Juan José } \\
\text { Nieto }\end{array}$ & 1.300 \\
\hline & La Paila & 150 & & $\begin{array}{l}\text { Severo } \\
\text { Mulato }\end{array}$ & 1.800 \\
\hline \multirow{3}{*}{$\begin{array}{l}\text { Puerto } \\
\text { Tejada }\end{array}$} & Río Palo & 1.500 & \multirow{3}{*}{ Villa Rica } & \multirow{3}{*}{$\begin{array}{l}\text { Territorio y } \\
\quad \text { Paz }\end{array}$} & \multirow{3}{*}{800} \\
\hline & $\begin{array}{c}\text { Cuenca río } \\
\text { Paolo y la Paila }\end{array}$ & 36 & & & \\
\hline & $\begin{array}{c}\text { Palenque } \\
\text { Monte Oscuro }\end{array}$ & 60 & & & \\
\hline
\end{tabular}




\begin{tabular}{|c|c|c|c|c|c|}
\hline Municipio & $\begin{array}{c}\text { Consejo } \\
\text { Comunitario }\end{array}$ & $\begin{array}{c}\mathrm{N} .^{\circ} \mathrm{de} \\
\text { familias }\end{array}$ & Municipio & $\begin{array}{c}\text { Consejo } \\
\text { Comunitario }\end{array}$ & $\begin{array}{c}\mathrm{N} .^{\circ} \text { de } \\
\text { familias }\end{array}$ \\
\hline \multirow{4}{*}{$\begin{array}{l}\text { Santander } \\
\text { de } \\
\text { Quilichao }\end{array}$} & $\begin{array}{c}\text { Aires de } \\
\text { Garrapatero }\end{array}$ & 1.375 & \multirow{4}{*}{ Villa Rica } & \multirow{4}{*}{$\begin{array}{l}\text { Quebrada } \\
\text { Tabla }\end{array}$} & \multirow{4}{*}{150} \\
\hline & $\begin{array}{c}\text { Cuenca río la } \\
\text { Quebrada }\end{array}$ & 2.014 & & & \\
\hline & $\begin{array}{c}\text { Zanjón de } \\
\text { Garrapatero }\end{array}$ & 650 & & & \\
\hline & Quapaq & $\begin{array}{c}\text { Sin } \\
\text { información }\end{array}$ & & & \\
\hline \multirow{4}{*}{ Suárez } & Las Brisas & $\begin{array}{c}\text { Sin } \\
\text { información }\end{array}$ & \multirow{4}{*}{$\begin{array}{c}\text { Buenos } \\
\text { Aires }\end{array}$} & Cerro Teta & 1.762 \\
\hline & Asnazu & $\begin{array}{c}\text { Sin } \\
\text { información }\end{array}$ & & La Alsacia & 1.475 \\
\hline & La Meseta & $\begin{array}{c}\text { Sin } \\
\text { información }\end{array}$ & & Río Cauca & 114 \\
\hline & La Toma & 1.500 & & $\begin{array}{c}\text { Senderos } \\
\text { de Buenos } \\
\text { Aires }\end{array}$ & 900 \\
\hline & Puerto & $\begin{array}{c}\text { Sin } \\
\text { información }\end{array}$ & & $\begin{array}{l}\text { Cuenca } \\
\text { Cauca }\end{array}$ & 3.600 \\
\hline
\end{tabular}

Fuente: Instituto de Estudios Interculturales, 2014

Anexo 2. Resguardos Indígenas del Norte del Cauca

\begin{tabular}{|c|c|c|}
\hline \multicolumn{2}{|c|}{ Resguardos Constituidos y en proceso de clarificación } \\
\cline { 1 - 1 } Municipio & Resguardo & \multirow{2}{*}{ Número de familias } \\
\cline { 1 - 1 } Caloto & \multirow{2}{*}{ Corinto López Adentro } & \\
\cline { 1 - 1 } Guachené & \\
\cline { 1 - 1 } Corinto & \\
\hline Padilla & & \\
\hline
\end{tabular}




\begin{tabular}{|c|c|c|}
\hline Resguardos & nstituidos y en proceso c & arificación \\
\hline Municipio & Resguardo & Número de familias \\
\hline Caloto & \multirow{4}{*}{ Corinto López Adentro } & \multirow{4}{*}{1.993} \\
\hline Guachené & & \\
\hline Corinto & & \\
\hline Padilla & & \\
\hline Santander de Quilichao & Canoas & 1.146 \\
\hline Santander de Quilichao & \multirow{2}{*}{ Guadualito } & \multirow{2}{*}{280} \\
\hline Buenos Aires & & \\
\hline Miranda & Cilia o La Calera & 763 \\
\hline Buenos Aires & \multirow{2}{*}{ La Concepción } & \multirow{2}{*}{346} \\
\hline Santander de Quilichao & & \\
\hline Caldono & La Laguna - Siberia & 921 \\
\hline Caldono & Tumburao & 117 \\
\hline Santander de Quilichao & \multirow{4}{*}{ Huellas } & \multirow{4}{*}{1.280} \\
\hline Caloto & & \\
\hline Guachené & & \\
\hline Jambaló & & \\
\hline Caloto & \multirow{3}{*}{ Jambaló } & \multirow{3}{*}{3.144} \\
\hline Toribío & & \\
\hline Jambaló & & \\
\hline Buenos Aires & La Paila-Naya & 203 \\
\hline Buenos Aires & Las Delicias & 433 \\
\hline Caldono & Las Mercedes & 152 \\
\hline Caldono & Quichaya & 533 \\
\hline \multicolumn{3}{|c|}{ Resguardos Coloniales } \\
\hline Caldono & Pueblo Nuevo & 4.333 \\
\hline Caldono & \multirow{2}{*}{ Pioya } & \multirow{2}{*}{2.620} \\
\hline Jambaló & & \\
\hline Caldono & \multirow{2}{*}{ Caldono } & \multirow{2}{*}{8.970} \\
\hline Santander de Quilichao & & \\
\hline
\end{tabular}




\section{I Controversia 205}

\begin{tabular}{|c|c|c|}
\hline Caldono & \multirow{2}{*}{ Munchique } & Sin información \\
\cline { 1 - 1 } Santander de Quilichao & \multirow{2}{*}{ Pitayó } & \multirow{2}{*}{ Sin información } \\
\cline { 1 - 1 } Caldono & \multirow{2}{*}{ La Aguada } & \multirow{2}{*}{ Sin información } \\
\hline Jambaló & & \\
\hline Caldono & San José & 6.707 \\
\hline Jambaló & San Francisco & 6.880 \\
\hline Santander de Quilichao & Toribío & 12.878 \\
\hline Jambaló & Tacueyó & \\
\cline { 1 - 1 } & &
\end{tabular}

Fuente: Instituto de Estudios Interculturales, 2015 